\title{
Using the How People Learn Framework to Examine Mentoring Conversations between Special Educators and their Mentors in an Electronic Mentoring Site
}

\author{
Roberta Gentry \\ University of Mary Washington, USA
}

\begin{abstract}
This exploratory study examined the frequency and content of text-based interactions between special education mentors $(n=22)$ and mentees $(n=50)$ within an electronic mentoring site, the Electronic Mentoring for Student Success Program (eMSS). Mentors and mentees were matched based on grade level and disability category of students taught. The How People Learn (HPL) framework was used to qualitatively code conversations between novice teachers and their mentors. The HPL framework describes three essential competencies for teachers (1) knowledge of how students' learn; (2) knowledge of teaching; and (3) knowledge of subject matter [1]. This learning occurs within learning centered, knowledge centered, assessment centered, and community centered environments and is the place where teacher expertise develops [1]. Support for all aspects of this framework were found. Mentors and menthes communicated frequently sharing ideas and resources. A total of 997 postings were made during the five-month pilot program. Mentors initiated the majority of the posts $(n=675)$ and mentees initiated less often $(n=322)$. Data support mentoring conversations supporting all four environments. Learning centered $(n=909,36 \%)$; knowledge centered $(n=818,32 \%)$ assessment centered $(n=587,32 \%)$ and community centered $(n=213,8 \%)$. These data revealed that mentors provided specific support to beginning special educators with less than three years of teaching experience. Mentors provided support with lesson planning, behavior management, resources, compiling student data, interpreting student data, grading, and building content knowledge. Implications for future research and implications for practice will be discussed.
\end{abstract}

\section{Introduction}

The first year of teaching influences teachers' development and their decision to continuing teaching [2]. Traditionally, novice teachers have been matched with a school based mentor; however, these relationships are limited to the expertise within their buildings and for many special educators, it is not possible to be matched with a mentor teaching similar students. Additionally, as mentoring programs have been widely implemented and increased support is correlated with intent to stay in teaching [3] and retention [4]; the attrition rates

remain high among special educators. In fact, within special education, attrition is the major contributing factor to the inadequate supply of teachers. Research supports that $30 \%$ leave within the first three years and $50 \%$ within the first five years. In fact, special educators are two and a half times more likely to leave than teachers in other disciplines [5], [6]. Retaining a stable special education teaching force is critical to the quality of student learning, especially in light of persistent achievement gaps between students with disabilities and their peers [7].

One of the greatest challenges for new teachers is the need to be proficient from the moment they enter the classroom [8]. New teachers have the same expectations and responsibilities as an experienced teacher and pre-service education does not fully prepare them for this reality. Beginning teachers need ongoing developmental support to build their knowledge, skills, and dispositions. Therefore, mentoring programs are the critical link between theory learned during pre-service training and application in the school setting. Electronic mentoring, defined as "a relationship between a more experienced individual and a less skilled or experienced individual primarily using computer mediated communication is intended to develop and improve each mentee's skills, confidence, and cultural understanding [4]. While this concept is fairly new to education, it has been implemented in other fields, mainly business, for numerous years with positive results [3], [7], [8]. Electronic mentoring offers several distinct advantages including flexibility whereby mentors and mentees can connect when needed, regardless of geographical location and time constraints, in a format that mimics and expands traditional face to face interaction and in a way that increases solutions while simultaneously reducing costs of implementation and access [9]. Additionally, trained mentors can be drawn from a much larger pool of seasoned teachers than that typically available in local schools. This is especially important within special education where a beginning teacher may be the only person in their school teaching students from a particular disability category.

\section{Electronic Mentoring (E-Mentoring)}

The effectiveness of mentoring is closely aligned to the expertise of the mentor as well as the quality 
and type of support provided to beginning teachers [10]; however, studies support that the primary content of support is emotional support [1]. While mentees rate emotional support high and it has been associated with retention, Feiman-Nemser points out that "keeping new teachers in teaching is not the same as helping them become good teachers" [11, p. 25]. In order to assist new teachers with generalizing and applying the knowledge gained during preservice education, mentors need to focus on curriculum planning and instructional delivery; however, this is lacking in mentoring relationships. The content of mentoring conversations has predominantly been emotional support for mentees.

Electronic mentoring (e-mentoring) is intended to develop and improve each mentee's skills, confidence, and cultural understanding [3]. Ementoring offers several distinct advantages including flexibility whereby mentors and mentees can connect when needed, regardless of geographical location and time constraints, in a format that mimics and expands traditional face to face interaction and in a way that increases solutions while simultaneously reducing costs of implementation and access [8]. Additionally, trained mentors can be drawn from a much larger pool of seasoned teachers than that typically available in local schools.

E-mentoring involves the use of asynchronous and synchronous communication to support interaction between participants, allowing them to interact across geographical distances. It is designed to support novice teachers' needs through differentiated experiences based of the mentee's needs and immediate concerns [12]. Others reported that while the usage of e-mentoring remains relatively low, users reported shifts in instruction and instructional practices, however these findings were based on teacher self-reports [13]. The current study examined the transcripts of conversations between beginning special educators and their mentors in an e-mentoring site designed for special educators.

\subsection{The Electronic Mentoring for Student Success Program (eMSS)}

The eMSS program was developed in 2002 by the New Teacher Center. Originally designed to support science and math teachers, the program was expanded to support special educators in 2009. "Through eMSS mentors and mentees collaborate in an interactive and facilitated professional learning community to exchange information, ideas, and experiences" [14, p.2]. Mentees are assigned a mentor from the same grade level that has experience working with students with disabilities similar to the mentee to interact electronically discussing pedagogy and content in a private discussion area. The online forum of electronic mentoring represents a complex learning environment in which collaboration is practiced in a technologically mediated environment. This type of support holds potential for a form of collaborative work in which individuals can create knowledge; however the efficacy of its use remains mainly untested in education [15].

\section{Conceptual Framework: How People Learn (HPL)}

According to the HPL framework, effective teaching requires specialized knowledge of the learners, the learning process, curriculum and pedagogy [1]. With an emphasis on teacher development within a professional community, the HPL framework provides a "set of lenses on any teaching situation that teacher's can use to reflect on and improve their practice [1, p.10). Within this approach, transforming teaching and learning is based on understanding that teachers need to develop tools for assessing students' thinking, understand how they think, assess students' prior knowledge, and connect with students' families and communities [1]. Furthermore, professional development research supports that teachers need learning opportunities grounded in their daily work with students, related to their teaching and learning of curriculum content, organized around real problems of practice, and sustained over time by conversation and coaching [1]. Darling-Hammond proposes that this teaching and learning cycle be viewed as a coherent system [1].

With an emphasis on current practices, real life problems, and curriculum, mentoring relationships provides an opportunity for these focused conversations. However, the primary form of mentoring support has been emotional support and extant literature focuses on traits of the mentor, proximity of the mentor, and overall ratings of mentoring experiences; not the content of mentoring conversations. Strong professional communities are built on teachers who regularly engaged in discussions with colleagues about their work. These extended conversations allow teachers to scrutinize their beliefs about teaching, learning, and instructional practices and ultimately examine assumptions basic to quality practice [6]. In turn, this reflection process leads to deepened understanding of the process of teaching. Given this collaborative, supportive environment; teachers open up their practice to scrutiny and ask questions about their practice which leads to a more analytical view of their own teaching practice. This discourse is a tool to socially construct knowledge by enabling the expression of ideas and collective knowledge building. In turn, the reflective communication has shown to have positive effects on the growth of teacher practice [11]. However, while reflection is the primary tool for facilitating the development of competence and ultimately expertise [9] beginning 
teachers must be provided a support structure and opportunities for reflection. Mentoring, specifically electronic mentoring (e-mentoring) may provide this structure.

Knowing that learning needs to continue once teachers enter the classroom, the HPL framework recognizes the need for continuous knowledge and skill building. This framework outlines three general areas of knowledge, skills, and dispositions that are important for every teacher to acquire within four overlapping environments [1]. The three general areas of knowledge, skills, and dispositions that are important for every teacher to acquire include: (1) knowledge of learners and how they learn and develop in social contexts; (2) conceptions of curriculum, content, and goals (understanding the subject matter and skills to be taught); and (3) an understanding of teaching in light of the content and learners to be taught, informed by assessment and supported by classroom environments [1, p. 10].

The HPL framework also describes four overlapping environments that are used to analyze learning situations. These environments are called learner centered, knowledge centered, assessment centered, and community centered learning environments [1]. Learning centered environments incorporate the learners' strengths and interests and are designed to help students make connections between their previous knowledge, skills, attitudes, and beliefs. These environments provide a framework for student's construction of meaning by connecting new knowledge to old knowledge. The second environment knowledge centered, are standards based and organized around big ideas and are facilitated by providing rigorous content and assistance with helping students' understand a subject or discipline. Assessment centered environments are designed to enhance understanding of content through frequent opportunities for feedback, reflection, and revision to enhance learning. The final environment, community centered, includes the provision of a supportive, stimulating, and safe environment in which students challenge themselves. These supportive environments allow teachers to apply what they learned in pre-service teacher preparation programs to their current classrooms and the problems encountered in those classrooms. Thus, providing conductive settings for learning to teach [1].

Mentoring provides opportunities for the types of discussions outlined in the tenets of the HPL framework; conversely, no examinations currently exist. In spite of this, findings from previous studies lend support for the use of HPL as a lens for examination of mentoring conversations. Based on surveys, mentoring programs have been related to beginning teacher's self-ratings of their preparedness to teach, pedagogical content knowledge, and ability to manage classrooms [1]. The personal characteristics of mentors was reported by mentees as one of the most important factors associated with successful mentoring [16] and beginning special educators prefer mentors teaching students with similar disability characteristics [17]. Matching mentors with mentees' in the same field, with common planning time, and external networks contributed to teacher retention [6]. The current study examines conversations between special education teachers serving as mentors and their mentees in an e-mentoring site. The HPL framework is used to examine the content of those conversations.

\section{Methods}

The study examined conversations occurring between experienced special educators serving as mentors and their mentees. Transcripts of conversations were acquired after approval from the Institutional Review Board and analyzed qualitatively. Transcripts contained all asynchronous communication between mentors and mentees within the eMSS program. Content analysis of transcripts was the primary data source. Additional demographic information was also provided and will be discussed in this section. The research questions examined were: (1) What is the frequency of interactions between mentors and mentees in an electronic mentoring site; and (2) What is the content of the discourse between mentors and mentees related to the HPL framework? Findings of this study are part of a larger research effort examining the nature of interactions between special education mentors and mentees in an electronic mentoring site.

This section contains information about the eMSS program followed by information about the participants, instrumentation, and procedures. To address the frequency of interactions, interactivity was examined. This study utilized the text-based interactions between special education mentors and mentees within the eMSS platform developed by the New Teacher Center. This web-based electronic mentoring site focuses on improving novice teachers' content and pedagogical content knowledge [18] thus moving beyond the provision of emotional support with a focus on instructional practices and curriculum content. Mentees are assigned a mentor from the same grade level and discipline and interact electronically through one-on-one and small group communications discussing pedagogy and content.

\subsection{Participants}

Mentors, experienced teachers with strong content area knowledge and evidence of exemplary teaching, were partnered with a mentee with three years or less of classroom experience. Both mentors $(n=22)$ and mentees $(n=50)$ taught the same grade level and 
students with similar disabilities. Mentors and menthes were from two states in the United States. Mentees interacted with their mentors in an area of the site titled "Our Place." This area provides a private discussion area for the mentee and mentor to dialogue asynchronously individually and in groups containing one mentor and up to three mentees. Special educators with experience ranging from six to 21 years served as mentors. Mentees were in their first three years of teaching. In this examination, the majority of mentees $(n=9)$ stated this was their first year of teaching. Additionally, seven reported that it was their first year of teaching special education thus, for $17(76 \%)$ of the mentees this was their first year teaching special education. Six mentors reported having a Bachelors degree, seventeen had a Masters and one had a Doctorate degree. Mentors received stipends of $\$ 800$ to $\$ 1,000$ dependent on the number of mentees they were matched with and successful completion of an online mentoring institute. The majority of mentees had a Bachelor degree $(n=15)$, four indicated that they had a Masters degree and three stated that they had a doctorate. One mentee reported that they were not a certified teacher and an additional ten indicated that they were not certified to teach the population of students they were currently teaching. Mentors and mentees taught students with a variety of exceptionalities. Thirteen mentees and 15 mentors indicated that they taught students with learning disabilities. Twelve mentees and 15 mentors indicated that they taught students with mild/moderate disabilities. Eight mentees and 16 mentors taught students with emotional disabilities. Finally, 13 mentors indicated that they taught students with other disabilities and 10 mentees taught students with autism. The percentages exceed $100 \%$ percent due to mentors and mentees both teaching students from more than one disability category.

\subsection{Procedures}

Transcripts were provided electronically and were copied and pasted using a word processing software package. To address the first research question pertaining to frequency of interactions, frequency counts were performed utilizing the transcripts. For the purpose of this study, frequency counts were defined as mentor and mentee initiated posts. To address the research question pertaining to the specific content of the discourse occurring between special education mentors and mentees, conversations between mentoring partnerships were examined to identify themes and patterns as they pertain to the HPL framework. By doing so, the researchers could ascertain the frequency of each theme within the analyzed documents. The statistical software program, SPSS 18 was used to create frequency counts, means, and standard deviations and nVivo19 was used to qualitatively code data. Once all data was uploaded into nVivo, discussions between mentoring partners and groups were analyzed and coded based on themes related to the HPL framework (see Table 1). Second and third raters were utilized to address issues of reliability in the content analysis. Cohen's Kappa was performed to determine interrupter reliability.

\section{Data Analysis}

Discourse is crucial to understanding the learning that takes place in an online discussion area [20]. Discourse analysis is a well tested method for study of online learning [20] and has been applied by a number of researchers to gauge participant learning [19] [20]. Multiple means of conducting discourse analysis are available and agreement within the field on the best method of discourse analysis is lacking. In the current study, Henri's method was utilized. She developed an instrument to examine the social development of learning in online environments and places a strong emphasis on understanding social interactions of learners within a collaborative community [21]. Henri suggests dividing individual messages into statements corresponding to units of meaning. Therefore, each message could contain several different coded units. This method of discourse analysis was applied to a researcher created coding schema based on the HPL framework. The coding schema was developed based on an extensive literature review. Codes were based on descriptions of each of the communities described in the HPL framework: learner center, knowledge centered, assessment centered, and community centered. See Table 1 below for more detailed description.

\section{Results}

Two research questions guided this study. The research questions examined were: (1) What is the frequency of interactions between mentors and mentees in an electronic mentoring site; and (2) What is the content of the discourse between mentors and mentees related to the HPL framework? To answer these questions, the results are organized into two sections. The first section outlines the frequency of interactions occurring within the e-mentoring site and frequency of interactions specifically related to the HPL framework and the second section is analysis of the discourse.

\subsection{Interactions}

This analysis was driven by the first research question. As stated previously, this study is part of a 
Table 1. How People Learn Framework Coding Schema

\begin{tabular}{|c|c|}
\hline Environment & Examples \\
\hline Learner centered & $\begin{array}{l}\text { - knowledge, skills, attitudes and beliefs of learners } \\
\text { - misconceptions are discussed } \\
\text { - acknowledges background knowledge } \\
\text { - student thinking in relation to the problems } \\
\text { - providing situations to allow learners to adjust ideas } \\
\text { - recognition of the importance of cultural contexts } \\
\text { - expressing multiple intentions } \\
\text { - connecting everyday talk and school talk } \\
\text { - initial assumptions } \\
\text { - building on what students already know }\end{array}$ \\
\hline Knowledge centered & $\begin{array}{l}\text { - standards based } \\
\text { - organized around big ideas } \\
\text { - focused on information and activities that help learners develop an understanding } \\
\text { of the subject or discipline } \\
\text { - introduces knowledge } \\
\text { - emphasis on sense making and metacognitive skills } \\
\text { - learning with understanding }\end{array}$ \\
\hline Assessment centered & $\begin{array}{l}\text { - providing feedback about misconceptions and performance } \\
\text { - reflection and revision } \\
\text { - formative and summative assessments } \\
\text { - determine the effectiveness of learning methods } \\
\text { - self-assessment of learning }\end{array}$ \\
\hline Community centered & $\begin{array}{l}\text { - a collaborative learning environment } \\
\text { - goals and expectations are explicit } \\
\text { - learning goals established } \\
\text { - stimulating, supportive, and safe environment } \\
\text { - evidence of student's challenging themselves } \\
\text { - lifelong learners }\end{array}$ \\
\hline
\end{tabular}

Note: Adapted from Bransford, Brown, and Cocking (2000) and Darling-Hammond and Bransford (2005) and the IRIS Center for Training Enhancement (n.d). [1], [2], [22]

larger examination of the e-mentoring site. Therefore, totals for the site are reported followed by totals pertaining to specific portion of the site pertaining to the current examination. During the five-month pilot program a total of 1,928 postings were made in all areas of the online mentoring site. Most of the postings were made by mentors $(66 \%$; $\mathrm{n}=1,277)$ and mentees made fewer postings (24\%; $\mathrm{n}=465$ ). The focus of this study was the private paired mentor-mentee area of the site called Our Place. Within Our Place, there were a total of 997 postings were initiated by mentors and mentees. Mentors initiated $675(68 \%)$ and $322(33 \%)$ postings were initiated by mentees. As reported in Table 2 below, not only were there large differences between the overall amount of postings that mentors and mentees made in the site, there were large variability between the two as well.

\section{Discourse Analysis}

Qualitative analysis of the 997 postings initiated by mentors and mentees within the private areas of the eMSS site yielded a total of 2,527 segments coded as pertaining to the HPL framework (see Table 1). A coding system was developed by the researcher based on an extensive review of literature on HPL. The initial coding was tested with $25 \%$ of the data and changes were made to the coding schema. The researcher and two additional persons coded the dated and discussed changes based on initial inter-rater reliability of $78 \%$ and $80 \%$. Once changes were made, an additional $25 \%$ of data was coded by the researcher and two additional coders and inter-rater reliability increased to $97 \%$ and $98 \%$. With the final coding, Twenty-five percent of all content analysis was coded by a second rater, and if discrepancies were found, a third coder was used. Interrater reliability, reported as percentage agreement and Cohen's Kappa was calculated. 
Table 2. Mean, range, and standard deviation of mentor and mentee postings

\begin{tabular}{|lccc|}
\hline Role & Mean & Range & Standard Deviation \\
\hline & & & 15.44 \\
\hline Mentors & 32.14 & $6-61$ & 6.51 \\
\hline Mentees & 6.44 & $0-24$ & \\
\hline
\end{tabular}

Table 3. Frequency of Postings by HPL Framework

\begin{tabular}{lc} 
Framework & Total Postings \\
Learner Centered & 909 \\
Knowledge Centered & 818 \\
Community Centered & 213 \\
Assessment Centered & 587 \\
\hline Total & \\
\hline
\end{tabular}

Cohen's Kappa ranges from 0 to 1.0 where larger numbers mean more reliability, values near or less than zero suggest that agreement is attributable to chance alone. Cohen's Kappa was performed and reported. The results of interrater analysis are: Kappa $=0.94$ with $\mathrm{p}<0.001$ for HPL. Mentors and mentees discussed items included in the Learner Centered (36\%); Knowledge Centered (32\%); Community Centered (8\%); and Assessment Centered $(23 \%)$ environments that encompasses the HPL framework (see Table 3). The data supports that mentors provided assistance across all themes with support mainly provided for supporting learners (students), building knowledge, and assistance with assessments. These data revealed that content specific support was provided by mentors to beginning special educators. It seems that the content specific nature of the support focused the conversations on student learning rather than mentee's emotional needs. Learning centered environments accounted for the majority of coded segments. Mentors asked mentees clarifying questions such as, "Can I ask a few clarifying questions? Is this student choosing to be lazy due to his slow processing or is he being perceived as lazy by others due to his processing?" One mentees described that $90 \%$ of her class was boys and described them as "liking bugs, insects, and building things, as well as seasonal sports". Based on this knowledge and attempting to motivate them, she organized her curriculum around the seasons of the year and integrated authentic learning activities with embedded vocabulary and simultaneously integrated their personal interests. Another mentee described a student with autism "shutting down" in class and refusing to participate any longer. Through the assistance of her mentor, they created a daily schedule which allowed the student to check off or cross off completed tasks. At the bottom of the task list was a preferred activity and when the checklist is completed, the student completed her preferred activity. Previously when the student shut down in class, the teacher stated that they engaged in "a battle of the wills" which was not productive. After implementing a new plan developed through conversation with the mentor, the mentee stated, "it helped tremendously". Another mentee described a "difficult to motivate" student in her class and her mentor inquired about the student's background. Initially, the mentee was unaware of the student's educational history, but gained this foundational knowledge after the conversation and used it to inform instruction. She replied to the mentor "getting to know his background and prior knowledge was key to helping him succeed".

Knowledge centered environments are standards based, organized around big ideas, and focused on information and activities that help learners develop an understanding of a subject or discipline. Metacognitive skills are emphasized as well as learning with understanding rather than restating factual information. Examples include a mentee describing hosting a roller skating party as a means of working on mobility and communication skills as well as making change for a unit on money. Another mentee discussed using more nonfiction text with students after ascertaining the amount of fictional text used in the general education classroom. She stated this change "resulted in challenging work for students with learning disabilities". Another mentee reflected on the use of theme-based units and stated "next year, I will do a much better job of making 
explicit connections for the students". Another mentor suggested to a mentee "by using Learning Style Inventories you can hone in on the learning styles of your students and create activities that address the student's specific learning styles. Using activities that address the specific learning styles of your students in which they can become active participants. These strategies also address long term comprehension and allow students to build upon their knowledge".

Assessment centered learning environments provide feedback on misconceptions, allowing learners to reflect and revise and also involves selfassessment of learning. A total of 587 segments were coded as assessment centered. One mentor suggested the use of a portfolio with student work samples and assessments to allow students to recognize their progress. Frequently mentors and mentees shared their systems for monitoring student academic progress. Mentors and mentees discussed the use of binders, folders and software packages to electronically monitor student progress. A mentor stated that the software also allowed for easy creation of charts and graphs to share at meetings, with students, and with their parents. One mentor described "to monitor student progress, each student has an individual file with their targeted objectives for each academic area. I graph their daily activities - percentage, date, and brief description (i.e. two digit addition with regrouping) and at the end of the nine weeks [marking period], I use the data to write progress reports. This is very manageable and not time consuming". Another described using graphing to determine regression. Lastly, a teacher described and shared a form that she created for all general education teachers to track students' academic progress and stated that with this system "there are no surprises at the end of the six weeks [marking period]".

Community centered environments are ones where goals and expectations are explicit and defined. These are supportive, stimulating, safe environments where students are active participants and challenge themselves and become lifelong learners. A total of 213 portions of messages were coded as community centered. One mentees described their school settings as a "very supportive atmosphere that strives to work together to increase student performance". A mentor, introduced herself to the two mentees within the mentoring site, described creating a true community among herself and the two mentees. Another mentee stated that she was not the only one with good ideas and stated that she hoped the group could all learn together. Another mentee described a roller skating event she attended with her students. She stated, "out of the 75 kids attending there were maybe 10 that were verbal. No matter how limited their communication skills were the kids enjoyed meeting and interacting with new friends. They communicated with facial expressions, gestures, and vocalizations in addition to any augmentative communication they may have been using. They loved it!" The least amount of segments of postings was coded within the community centered environment of the HPL framework.

The HPL framework, which establishes principles of effective learning environments, was used to qualitatively code data within an e-mentoring site for special education teachers and their mentees. Support for all environments within the HPL framework was found. Mentors and mentees discussed planning instruction, reflected on lessons implemented, shared resources, and student academic progress was frequently discussed. Research suggests that online learning happens through active collaboration in online dialogue [21] and the eMSS site proved to be conducive for conversations among mentors and mentees. Additionally, typically in the beginning of mentoring conversations, all mentors asked mentees to describe their classroom makeup in terms of number of students, disabilities represented, cultural background, academic levels, and gender which seemed to focus conversations on the students and the learning environment from the beginning.

\section{Discussion}

The purpose of this study was to investigate the frequency of interactions and content of interactions between special education mentors and their mentees in an electronic mentoring site. A researcher reported that fewer than half of the 374 first year teachers across three states surveyed reported having a mentor in their same subject area and less than sixty percent of respondents stated they had three or more conversations with their mentor about classroom instruction, curriculum and lesson planning, or behavior and discipline during their mentored year [21]. Additionally, findings from previous research indicated that beginning teachers feel unprepared in curriculum and standards and the implementation of school accountability measures [9] and that early career teachers' value mentoring that supports their planning needs [3] [4]. The online discourse provided insight into the specific content discussed, how often specific categories of content were discussed, and the amount of overall interactions occurring between mentors and mentees. The ementoring platform allowed for examination of conversations and proved to be a valuable environment for this examination.

Effective professional development opportunities involve active learning, collaboration, and reflection that is congruent with teachers' daily lives [1]. The ease of communication has been presented as an advantage of online mentoring allowing mentors and 
mentees to $\log$ in anytime from anywhere and ask a question or respond to a question posed. Conversely, with more traditional forms of mentoring, mentees have to wait until a planning period or the end of the day to pose questions. Within the five-month pilot program, mentors posted 1,277 messages and mentees posted 465 [22]. That examination of a yearlong electronic mentoring site revealed a total of 526 postings between 11 mentors and 80 mentees which is a much lower number than the current examination. However, findings from this study supported findings that mentors initiated the majority of postings. In the other examination mentors made $71 \%$ of the postings and $29 \%$ were by mentees [22]. The current study had mentor participation rates of $66 \%$ in the entire site and $68 \%$ in the private portion of the site for mentoring purposes. In the eMSS site, mentors were partnered with up to three mentees and mentors responded each time a mentee posted accounting for some of the variability. Another researcher examined interactivity between math and science teachers using the eMSS site and reported that participants posted 9,307 messages during an academic year [9]. Perhaps the structure of the eMSS e-mentoring site provides supports for increased conversations.

The content of the interactions between mentors and mentees was also examined. Interactions led to knowledge building and specifically to assisting the mentee to understand teaching within their current contextual factors. Professional development literature tells us that beginning teachers need learning opportunities connected to the work of students, organized around real problems, within sustained and supportive environments [1] and this site provided that environment.

\section{Limitations and Implications for Future Research}

Based on the current examination, it is evident that both experienced and novice special educators enjoyed communicating, sharing resources, and gaining knowledge from one another in the online environment. The level of interactivity within the eMSS program appears to be higher than other ementoring programs. An unanticipated finding was that mentors posted more frequently than mentees that lends support to previous findings [22]. This phenomenon warrants future examination. Perhaps an online professional learning community for experienced teachers to continue their professional growth and development is warranted. Furthermore, based on findings from this study and previous examinations, possibly the eMSS site solicits higher response rates than other online mentoring programs and a comparison study could examine this in the future [9].
Mentee participation declined towards the end of the pilot program (which coincided with the end of the school year). While only overall interactivity was the focus of the current examination, future studies could explore interactivity over time. Additionally, if changes in participation over time are discovered, interviews might be used to explore this phenomena further in future examinations. A mentee in the current study stated, "I was not able to participate as much as I hoped because the end of the year paperwork prohibited me from participating as much as I would have liked to". Does the decline in participation relate to the time of year and the amount of work involved in closing out a year, as suggested by this participant, or was it that they had most of their questions answered and no longer needed as much assistance from mentors? Other researchers noted a decline in mentee postings during a yearlong examination beginning in March [22]. Further examination into interactivity by week or month would assist with determining if time of year is a factor in levels of participation. If a decline in participation is found, survey or interview questions specifically asking participants about this phenomenon could be a topic for future examination. Another phenomena identified in previous studies is referred to as "lurkers" or "peripheral participants". These are individuals who visit the site, read the postings, but do not participate. At the time of this study, the site could not account for the amount of time or the number of logins made by each individual, but it has since been updated to include these features so this phenomena can be examined in future studies within this site and beyond the site. Several mentees commented on reading other participants postings within this study. Researchers have suggested that beginning teachers may engage in this behavior as an opportunity to learn the norms of the online environment [17], [19]. Finally, a researcher who also examined the eMSS site also reported that numerous participants stated they read responses posted by others, but they did not respond [9]. Perhaps additional training in participation in an online mentoring site is required.

Another limitation is that this research focused only on communications with electronic mentors. Mentees were presumed to have mentors assigned by their respective schools and information was not obtained about the content or frequency of those interactions. Future studies that partner a mentee with local mentor and an electronic mentor could examine what types of support sought and provided by each. Additionally, examining if there are pattern in seeking help from face-to-face mentors versus ementors surrounding specific questions would be beneficial. Previously, it has been suggested that future research could identify more clearly the differences between communication with face-toface mentors and e-mentors [22]. 
A comparison e-mentoring site was not used in this research. This study examined one site, therefore it is not known if the HPL framework would provide insight into other mentoring sites or into traditional forms of mentoring. As mentioned previously, the level of interactivity was high comparatively, especially considering its short duration; however, a comparison site would provide insight into if the structure of the site increased participation rates or if other variables accounted for the participation rates. Also, the relatively short duration of the pilot study was a limitation. The pilot program began in February rather than the start of the school year. Future studies could examine levels of interactivity throughout an entire academic year for patterns that emerge. Also, this study used the amount of postings by mentors and mentees to determine frequency of postings; however, these postings may be short and lack reflection. Likewise, participants may post infrequently, but each posting providing depth and reflection.

Based on the level of interactivity and the content and student focus support, school systems may consider developing an online repository for resources and materials as well as establishing online discussion areas. This might especially be helpful when special educators are working with students with low incidence disabilities. Often these teachers are the only individuals in their school teaching students with these characteristics. Perhaps a mentor miles away teaching students with similar characteristics might be more helpful with lesson planning and resources than a mentor within the building, but without direct experience teaching students with these disabilities. Perhaps a mentoring triad with a school based mentor, an electronic mentor to support a mentee with emotional supports and building level processes as well as an expert to consult for content or specific information on characteristics of students with specific disabilities. Finally, effective mentoring programs aim to improve knowledge, skills and dispositions that will subsequently impact student achievement. Student outcome data could be collected on mentee's students.

This study explored the frequency and content of interactions between special education mentors and mentees in an e-mentoring program. The content of dialogue among mentors and mentees were examined using the HPL framework. Research supports that effective professional development opportunities for teachers involve active learning, collaboration, and reflection and are congruent with teachers' daily lives [1]. The HPL framework, which establishes principles of effective learning environments, was used to examine the content of the discourse. The HPL framework involves groups collectively and singularly applying learning to relevant situations. This complex problem solving approach is socially meditated allowing person to test solutions through structured learning opportunities. Within the online environment, learning occurs through active collaboration in online dialogue [17].

\section{References}

[1] Bransford, J. D., Brown, A. L., \& Cocking, R. R. (Eds.). (2000). How People Learn: Brain, Mind, Experience and School. Washington, DC: National Academy Press.

[2] Nemser, S. F. (1983). Learning to teach. In L. S. Shulman \& G. Sykes (Eds.), Handbook of teaching and policy (pp. 150-169). NY: Longman.

[3] Gersten, R., Keating, T., Yovanoff, P., \& Harniss. M. K. (2001). Working in special education: Factors that enhance special educators' intent to stay. Exceptional Children, 67(4), 549-567.

[4] Smith, T. M., \& Ingersoll, R. M. (2004). What are the effects of induction and mentoring on beginning teacher turnover? American Educational Research Journal, 41(3), 681-714.

[5] Brill, S., \& McCartney, B. (2008). Stopping the revolving door: Increasing teacher retention. Politics \& Policy, 36(5), 750-774. doi: 10.1111/j.17471346.2008.00133.x

[6] Butler, K. (2008, December). Desperately seeking special ed teachers. District Administration. Retrieved on January 2, 2009, from

http://www.districtadministration.com/viewarticle.aspx?art icleid $=1777$.

[7] Pugach, M. C., Blanton, L. P., Correa, V. I., McLeskey, J., \& Langley, L. K. (2009). The role of collaboration in supporting the induction and retention of new special education teachers (NCIPP Document Number RS-2). Gainesville, FL: National Center to Inform Policy and Practice in Special Education Professional Development.

[8] Kealy, M. V. (2010). A leadership focus on teacher effectiveness. Journal of Special Education Leadership 23(1), 52-54.

[9] Parker-Katz, M., \& Hughes, M. T. (2008). Preparing special education mentors using classroom artifacts as a vehicle for learning about teaching. Teacher Education and Special Education, 31(4), 268-282.

[10] Gehrke, R. S., \& McCoy, K. (2007). Sustaining and retaining beginning special educators: It takes a village. Teaching and Teacher Education, 23, 490-500. doi: 10.1016/j.tate.2006.12.001

[11] Feiman-Nemser, S. (2001). From preparation to practice: Designing a continuum to strengthen and sustain teaching. Teachers College Record, 103(6), 1013-1055. 
[12] Smith, S. J., \& Israel, M. (2010). E-mentoring: Enhancing special education teacher induction. Journal of Special Education Leadership, 23(1), 30-40.

[13] Gentry, L. B., Denton, C. A., Kurz, R. (2008). Technologically-based mentoring provided to teachers: A synthesis of the literature. Journal of Technology and Teacher Education, 16(3), 339-373.

[14] Kepp, L., \& Myke, A. (2009). eMSS: An online, content focused mentoring program for secondary math and science teachers [White paper]. Retrieved from The New Teacher Center website, http://www.newteachercenter.org/pdfs/eMSS_whitepaper. pdf

[15] Kanuka, H., \& Anderson, T. (1998). Online social interchange, discord, and knowledge construction. Journal of Distance Education, 13(1), 57-74.

[16] Whitaker, S.D. (2003). Needs of beginning special education teachers: Implications for teacher education. Teacher Education and Special Education, 26(2), 106-117.

[17] Farrar, B. L. (2009). Elements of reflective and nonreflective discourse in an online induction program for experienced and novice science teachers (Doctoral dissertation).

[18] Kanuka, H., \& Anderson, T. (1998). Online social interchange, discord, and knowledge construction. Journal of Distance Education, 13(1), 57-74.

[19] Gunawardena, C., Plass, J., \& Salisbury, M. (2001). Do we really need an online discussion group? In D. Murphy, R. Walker, \& G. Webb (Eds.), Online learning and teaching with technology: Case studies, experience, and practice (pp. 36-43). London: Kogan Page.

[20] Henri, F. (1992). Computer conferencing and content analysis. In A. Kaye (Ed.), Collaborative learning through computer conferencing: The Najaden papers (pp. 117-136). Berlin, FRG: Springer-Verlag.

[21] Kardos, S. M. \& Johnson, S. M. (2010). New teachers experiences of mentoring: The good, the bad, and the inequity, Journal of Educational Change, 11, 23-44, doi:10.1007/s10833-008-9096-4 10.1007/s10833-0089096-4

[22] Gareis, C. R., \& Nussbaum-Beach, S. (2007). Electronically mentoring to develop accomplished professional teachers. Journal of Personnel Evaluation in Education, 20, 227-246. 